\title{
The Association Between Beliefs and Adherence to Inhaled Controller Medication Among Older Adults with Asthma: A Cross-Sectional Study in Primary Care
}

This article was published in the following Dove Press journal:

Patient Preference and Adherence

\author{
Changwei Liu' \\ Chee Wei Tham ${ }^{2}$ \\ Jacqueline De Roza' \\ Bee Yen Chong ${ }^{3}$ \\ Yi Ling $\mathrm{Koh}^{3}$ \\ Ngiap Chuan Tan $\mathbb{D}^{3,4}$ \\ 'National Healthcare Group Polyclinics, \\ Singapore; ${ }^{2}$ Yong Loo Lin School of \\ Medicine, Singapore; ${ }^{3}$ SingHealth \\ Polyclinics, Singapore; ${ }^{4}$ SingHealth-Duke- \\ NUS Family Medicine Academic Clinical \\ Programme, Singapore
}

Correspondence: Changwei Liu

National Healthcare Group Polyclinics, 2 I

Geylang East Central 389707, Singapore

Email Changwei_LIU@nhgp.com.sg
Background: While illness perceptions and medication beliefs have been shown to be associated with inhaled corticosteroid (ICS) adherence in younger adults with asthma, their impact on older adults is less understood. This study aimed to determine the prevalence of ICS adherence among older Asian adults and to assess the association between ICS adherence, illness perceptions and medication beliefs.

Methods: A questionnaire survey on older multi-ethnic Asian patients, aged $\geq 60$ years, with physician-diagnosed asthma, was conducted in two Singapore public primary care clinics. The scores of the Medication Adherence Report Scale for asthma (MARS) were computed to determine the adherence to ICS alone or in combination with LABA. Illness perceptions and medication beliefs were assessed by the scores from the Brief-Illness Perception Questionnaire (B-IPQ) and Beliefs about Medications Questionnaire (BMQ), respectively. Logistic regression analyses were used to identify factors associated with ICS adherence.

Results: Analyses of 323 participants (57\% males; Chinese $73.7 \%$, Malay $12.7 \%$, Indian $12.4 \%$; mean age 71.5 years) showed that $40.9 \%$ of them had good adherence to ICS (mean MARS score $\geq 4.5$ ). Good adherence to ICS was associated with perception of asthma as a chronic illness $(\mathrm{OR}=1.22 ; 95 \% \mathrm{CI}=1.10-1.35 ; p<0.001)$, belief of ICS as an essential medication $(2.67 ; 1.76-4.06 ; p<0.001)$ and fewer concerns about its use $(0.39 ; 0.26-0.60$; $p<0.001)$. Patients on combined ICS-LABA therapy had higher adherence $(2.50 ; 1.41-4.44$; $p=0.02$ ) than those on ICS monotherapy.

Conclusion: Four in ten older patients with asthma were adherent to ICS. Perception of medication necessity, chronicity of illness, concerns and use of ICS-LABA medication were associated with adherence.

Keywords: asthma, medication adherence, primary healthcare

\section{Introduction}

Poor adherence to asthma inhaled corticosteroids (ICS) or controller medication is a global problem, with studies reporting ICS adherence rates ranging from $30.0 \%$ to $70.0 \%{ }^{1-4}$ The variable adherence rates could be influenced by demographic, psychological, behavioural and socioeconomic factors. ${ }^{5-8}$ Low adherence to ICS leads to poor asthma outcomes and increased healthcare costs. ${ }^{5,9,10}$ This is especially worrisome among older patients due to increasing asthma-related morbidity and mortality with age. ${ }^{11,12}$ They tend to have more asthma-related emergency 
visits, hospital admissions and deaths compared to younger patients. ${ }^{11,12}$ Hence, it is pertinent to understand the factors influencing their adherence to ICS.

Perceptions of asthma appear to impact treatment adherence. Leventhal et al have described the "Common Sense Model", in which they reported that illness perceptions influenced self-management behaviour and adherence. ${ }^{13}$ In this model, patients form perceptions of their chronic illnesses, from what they have learnt from various sources. These illness perceptions are represented in five dimensions: 1) "Causes" refers to patient's understanding of the aetiology of the illness; 2) "Control" refers to the perceived extent to which the illness can be controlled; 3) "Consequences' relates to the perceived impact of the illness on patient's life; 4) "Timeline" means the perceived length of an illness; 5) "Identity" refers to the symptoms which patients attribute to their illness. ${ }^{13}$

Illness perceptions in the "Identity", "Timeline", "Control" and "Consequences" dimensions have been shown to be associated with adherence to asthma medications in younger adults. ${ }^{3,14-16}$ Using the Illness Perception Questionnaire, Byer et al showed that patients (mean age of 39.6 years) who perceived asthma as a long-term illness ("Timeline") and those who had many asthma-related symptoms ("Identity") were associated with better adherence to asthma medications. ${ }^{3}$ In contrast, patients who reported low perception of control over asthma ("Control") and those who perceived asthma as having few adverse consequences ("Consequence") had lower adherence to asthma medication. ${ }^{14} \mathrm{~A}$ study on Asian adults (mean age of 53 years) similarly found that greater perceived control over asthma was associated with higher adherence. ${ }^{15}$

Medication beliefs have also been shown to influence adherence to inhaled asthma medications in younger adults. ${ }^{14-18}$ Medication beliefs can be assessed using the Necessity-Concerns Framework, in which adherence is influenced by judgment of need for treatment (medication-Necessity) and concerns about treatment (medication-Concerns). ${ }^{19}$ Drawing on this framework, medication beliefs can be quantified using the "medication-Necessity" and "medication-Concerns" scales of the Beliefs about Medications Questionnaire which has been found to be useful for explaining medication nonadherence in many long-term conditions. ${ }^{19,20}$ Using this questionnaire on adults with mean age of 54.2 years, Cooper et al showed that patients with strong concerns about their treatment had lower adherence to asthma medication. ${ }^{17}$ In contrast, Van Steenis et al showed that patients (mean age 43.7 years) with firmer beliefs in the necessity of asthma medications had better adherence. ${ }^{21}$

Illness perceptions and medication beliefs are potentially modifiable by healthcare professionals via counselling to rectify their misperceptions and erroneous beliefs. Perceptions and beliefs are shaped by life experiences and social-cultural background of the individuals. We postulated that older patients could have different perceptions and medication beliefs, due to their longer experiences with asthma and its treatment, interactions with their healthcare providers, and influences from family and peers. In rapidly aging communities, including those in Singapore, understanding their illness perceptions and medication beliefs are vital to identify opportunities to improve their medication adherence and optimizing their asthma control. Many of these senior patients are treated in public primary healthcare centres (polyclinics) in Singapore, where they receive subsidized medications and counselling by multidisciplinary teams.

Hence, the primary aim of the study was to investigate the extent of adherence to ICS among older adults with asthma who were managed in local polyclinics. The secondary aim was to examine the association between their illness perceptions and medication beliefs in relation to their ICS adherence.

\section{Methods}

\section{Study Design and Setting}

This was an interviewer-administered questionnaire survey of older patients with asthma who were managed in polyclinics to evaluate their perceptions of asthma and beliefs about ICS. Patients, aged 60 years and above, with physician-diagnosed asthma and treated with ICS alone or in combination with Long-Acting Beta-Agonists (LABA), were invited to participate in the study. Patients who were on long-term inhalers for chronic lung diseases other than asthma or had current lower respiratory tract infections and who were unable to provide informed consent were excluded.

Potential patients were either referred by the polyclinic physicians or approached on a case-encounter basis by the polyclinic staff. Convenience sampling was used in this study. The investigator would ascertain each potential patient's eligibility and obtained his/her written informed consent after clarifying his/her doubts. Enrolled patients 
were administered the questionnaires to capture their demographic characteristics and scores of the instruments.

English and Chinese versions of the questionnaires were used. As the instruments in the questionnaire were validated overseas, the questionnaires were piloted to check face validity and content validity prior to the study commencement. Investigators who were to administer the questionnaire were trained by the principal investigator to ensure consistency.

The study sites included Geylang and Outram Polyclinics. Both are located in estates with higher proportions of senior residents and serve a combined population of 140,549 residents. $^{22}$ Recruitment period was from March 2017 to March 2018.

\section{Sample Size Calculation}

As there was no prior local data on ICS adherence among older adults in primary care, the $43 \%$ prevalence of good ICS adherence reported by Sofianou et al using MARS scores of $\geq 4.5$ to denote good adherence was used to estimate the sample size for this study. ${ }^{23}$ Data from the electronic health records shows 2230 senior patients with asthma at the study sites. A calculated sample size of 323 participants was required at 5\% precision and $95 \%$ confidence level based on 2230 finite population.

\section{Instruments}

\section{Medication Adherence Report Scale for Asthma (MARS)}

The Medication Adherence Report Scale for asthma (MARS) is a 10-item questionnaire that assesses selfreport of adherence to asthma controller. ${ }^{24}$ The MARS has been validated against electronic measures of adherence to asthma controller, and has been shown to have high inter-item reliability (Cronbach's $\alpha=0.85$ ) and good test-retest reliability $(\mathrm{r}=0.65, p<0.001){ }^{25}$ It consists of statements describing different aspects of non-adherent behaviour, rated on a 5-point Likert-type scale. Scores for each item were summed up and divided by ten to obtain a mean score, ranging from 1 to 5 .

\section{Brief-Illness Perception Questionnaire (B-IPQ)}

The original Illness Perception Questionnaire (IPQ) was first developed by Weinman et al which assessed the dimensions of illness perceptions. ${ }^{26}$ Adapting from the IPQ,
Broadbent et al developed a modified version, the B-IPQ, which has been validated for asthma. ${ }^{27}$ Patients' illness perceptions in the dimensions of illness "Consequences", "Timeline", "Control" and "Identity" were assessed using the B-IPQ in this study. These four dimensions were chosen as they demonstrated association with adherence to asthma controller in younger adults. ${ }^{3,14,16,18}$ Each item in the B-IPQ independently measures a dimension of illness perception and consists of a 11-point Likert-type scale from 0 to 10 . Higher scores signify a stronger belief in that dimension of illness perception.

\section{Beliefs About Medications Questionnaire (BMQ)}

Patients' beliefs about their ICS were assessed using the Beliefs about Medications Questionnaire (BMQ), which has proven validity for asthma. ${ }^{20}$ The BMQ consists of two scales, the "medication-Necessity" scale and the "medicationConcerns" scale. The "medication-Necessity" scale assesses patients' beliefs about the necessity of using their ICS for asthma, while "medication-Concerns" scale assesses patients' concerns about their ICS. Each scale consists of 5 items and respondents indicate their degree of agreement with each statement on a 5-point Likert-type scale. Scores obtained from the items in each scale were summed up and divided by the number of items to give a mean scale score ranging from 1 to 5 .

\section{Analyses}

Participants were categorized into two groups based on their MARS scores. MARS score $\geq 4.5$ and MARS score $<4.5$ denotes good and poor adherence, respectively, as defined by the literature. ${ }^{25} \mathrm{~B}-\mathrm{IPQ}$ and BMQ scores were treated as continuous variables. To assess ICS adherence between the participants' characteristics, Chi-square test was performed between categorical variables. To assess the association between B-IPQ and BMQ scores in relation to ICS adherence, independent $t$-test was performed for normally distributed variables.

All significant variables $(p<0.05)$ during the bivariate analyses were entered in the logistic regression modelling to explore the association of ICS adherence with illness perceptions and medication beliefs by controlling for other confounding demographic and clinical variables. A $p$-value of $<0.05$ was considered significant. Tests were 2-tailed $(\alpha=0.05)$. SPSS version 23 was used for the analyses. 
Ethics approval for this study was obtained from the SingHealth Centralized Institution Review Board (CIRB: 2016/3173/E). This study was conducted in accordance with the Declaration of Helsinki. Written informed consent was obtained from all participants in this study.

\section{Results}

\section{Participant Characteristics}

Three hundred and fifty-one eligible patients were approached, of which 28 declined participation, leading to an overall response rate of $92.0 \%$. Three hundred and twenty-three patients were included in the analyses. The mean age of the study population was 71.5 years $(\mathrm{SD}=8.0), 57.0 \%$ males, with Chinese forming the majority ethnic group (Table 1).

\section{Description of B-IPQ and BMQ Scores}

Our study showed that $64.1 \%$ of patients scored greater than midpoint on the B-IPQ timeline scale while $30.7 \%$ of them scored greater than midpoint on the BMQ-concerns scale (Table 2). Scores of individual items from the BMQconcerns scale showed that $42.0 \%$ of patients were worried about the long-term effects of their asthma medication, while $35.0 \%$ of them were concerned about becoming too dependent on them.

\section{Prevalence of ICS Adherence}

The results showed that $40.9 \%$ of patients had good adherence to ICS based on MARS cut off score of 4.5 (Table 1).

\section{Association Between Participants' Characteristics and Adherence}

Patients on combined ICS-LABA therapy were more adherent to their treatment compared to patients on ICS monotherapy based on the MARS scores $(p<0.001)$ (Table 1).

\section{Association Between Beliefs and ICS Adherence}

Patients with good ICS adherence viewed asthma as an illness with a longer timeline $(p<0.001)$, perceived greater control over asthma $(p<0.001)$ and had fewer concerns about their asthma medications $(p<0.001)$ compared to those with poor adherence. They also had higher medication-Necessity scores compared to patients with poor adherence $(p<0.001)$ (Table 2).

\section{Results of Logistic Regression}

The association of beliefs with ICS adherence was further examined in a logistic regression model by controlling for demographic factors (age, gender, ethnicity, education and housing) and significant confounding variables found during bivariate analyses (Table 3). Logistic regression analyses showed good ICS adherence was associated with perception of asthma as an illness with a longer timeline $(\mathrm{OR}=1.22 ; 95 \% \mathrm{CI}=1.10-1.35, \mathrm{p}<0.001)$, and ICS belief as being a necessity $(2.67 ; 1.76-4.06, p<0.001)$. Patients with good ICS adherence were less concerned about taking asthma medications $(0.39 ; 0.26-0.60, p<0.001)$. Patients on combined ICS-LABA therapy were more adherent to their treatment compared to patients on ICS monotherapy (2.50; 1.41-4.44; $p=0.02)$. Perceived control did not show statistical significance in this regression modelling.

\section{Discussion}

\section{Summary}

Less than half of the study population had good adherence to ICS based on self-report using the MARS scores. Patients on combined ICS-LABA therapy were more adherent to their medication compared to patients on ICS monotherapy. Patients' concerns and beliefs about the necessity of their asthma controller were significantly associated with adherence. Those who perceived asthma as an illness with a longer timeline were more likely to be adherent to ICS.

\section{Comparison with Existing Literature}

The prevalence of good adherence in this study was $40.9 \%$. This result was comparable to overseas studies with good adherence ranging from $30.0 \%$ to $70.0 \%{ }^{1-4,23}$ In this study, perceived asthma timeline was positively associated with adherence among older adults. This positive association was also reflected among younger adults. ${ }^{3,6}$ In a study by Foster et al on patients (mean age 47.6 years) attending community pharmacies and primary care clinics, perceived asthma chronicity was associated with both self-reported and electronically measured adherence. ${ }^{6}$ Findings by Byer et al among patients in a UK general practitioner practice (mean age 39.6) also supported this association between illness timeline with adherence. ${ }^{3}$ In contrast, Sofianou et al showed that patients who felt that "I will not always have asthma" had poorer adherence compared to those who disagreed with that statement. ${ }^{23}$ Patients with this perception not only had 
Table I Bivariate Analyses of Participants' Characteristics and Adherence

\begin{tabular}{|c|c|c|c|c|}
\hline Characteristics & Total n (\%) & Poor Adherence* n (\%) & Good Adherence ${ }^{* *}$ n (\%) & $p$ \\
\hline Total & $323(100.0)$ & $191(59.1)$ & $132(40.9)$ & - \\
\hline \multicolumn{5}{|l|}{ Age, years } \\
\hline $60-70$ & $165(51.0)$ & $10 \mathrm{I}(6 \mathrm{I} .2)$ & $64(38.8)$ & 0.437 \\
\hline$>70$ & $158(49.0)$ & $90(57.0)$ & $68(43.0)$ & \\
\hline \multicolumn{5}{|l|}{ Gender } \\
\hline Female & $140(43.0)$ & $80(57.1)$ & $60(42.9)$ & 0.524 \\
\hline Male & $183(57.0)$ & III (60.7) & $72(39.3)$ & \\
\hline \multicolumn{5}{|l|}{ Ethnic group } \\
\hline Chinese & $238(73.7)$ & $143(60.1)$ & $95(39.9)$ & 0.664 \\
\hline Malay & $4 \mid(12.7)$ & $21(5 \mid .2)$ & $20(48.8)$ & \\
\hline Indian & $40(12.4)$ & $24(60.0)$ & $16(40.0)$ & \\
\hline Eurasian/Others & $4(1.2)$ & $3(75.0)$ & I (25.0) & \\
\hline \multicolumn{5}{|l|}{ Education level $^{\wedge}$} \\
\hline No formal education/Primary school & $157(48.8)$ & $94(59.9)$ & $63(40.1)$ & 0.758 \\
\hline Secondary school and above & $165(5 \mathrm{I} .2)$ & $96(58.2)$ & $69(41.8)$ & \\
\hline \multicolumn{5}{|l|}{ Housing type } \\
\hline Rental/I/2-room public housing & $61(18.9)$ & $35(57.4)$ & $26(42.6)$ & 0.657 \\
\hline 3/4/5-room/Executive public housing & $216(66.9)$ & $126(58.3)$ & $90(41.7)$ & \\
\hline Private housing & $46(14.2)$ & $30(65.2)$ & $16(34.8)$ & \\
\hline \multicolumn{5}{|l|}{ Age of asthma diagnosis } \\
\hline$\leq 40$-year-old & $126(39.1)$ & $73(57.9)$ & $53(42.1)$ & 0.726 \\
\hline$>40$-year-old & $197(61.0)$ & 118 (59.9) & $79(40.1)$ & \\
\hline \multicolumn{5}{|l|}{ Smoking status } \\
\hline Current smoker & $27(8.4)$ & $18(66.7)$ & $9(33.3)$ & 0.504 \\
\hline Previous smoker & $56(17.3)$ & $30(53.6)$ & $26(46.4)$ & \\
\hline Never smoked before & $240(74.3)$ & $143(60.0)$ & $97(40.0)$ & \\
\hline \multicolumn{5}{|l|}{ Records of previous spirometry } \\
\hline Yes & $58(18.0)$ & $30(51.7)$ & $28(48.3)$ & 0.205 \\
\hline No & $265(82.0)$ & $161(60.8)$ & $104(39.2)$ & \\
\hline \multicolumn{5}{|l|}{ Inhaler device } \\
\hline Metered Dose Inhaler & $214(66.3)$ & $123(57.5)$ & $91(42.5)$ & 0.396 \\
\hline Dry Powder Inhaler & $109(33.7)$ & $68(62.4)$ & $41(37.6)$ & \\
\hline \multicolumn{5}{|l|}{ Inhaler medication } \\
\hline ICS monotherapy & $133(4 \mid .2)$ & $94(70.7)$ & $39(29.3)$ & $<0.001$ \\
\hline Combined ICS-LABA therapy & $190(58.8)$ & $97(51.1)$ & $93(48.9)$ & \\
\hline \multicolumn{5}{|c|}{ Frequency of asthma controller regime } \\
\hline Once a day & $90(27.9)$ & $53(58.9)$ & $37(4 I .1)$ & 0.956 \\
\hline$\geq 2$ times a day & $233(72.1)$ & $138(59.2)$ & $95(40.8)$ & \\
\hline \multicolumn{5}{|l|}{ Step of asthma treatment } \\
\hline Step 3 or less & $182(56.3)$ & $113(62.1)$ & 69 (37.9) & 0.220 \\
\hline Step 4 and above & $|4|(43.7)$ & $78(55.3)$ & $63(44.7)$ & \\
\hline \multicolumn{5}{|l|}{ Asthma Control Test (ACT) score } \\
\hline ACT $<20$ & $29(9.0)$ & $21(72.4)$ & $8(27.6)$ & 0.127 \\
\hline ACT $\geq 20$ & $294(91.0)$ & $170(57.8)$ & $124(42.2)$ & \\
\hline
\end{tabular}


Table I (Continued).

\begin{tabular}{|l|l|l|l|l|}
\hline Characteristics & Total $\mathbf{n}$ (\%) & Poor Adherence* $\mathbf{n}(\%)$ & Good Adherence** $\mathbf{n}(\%)$ & $\boldsymbol{p}$ \\
\hline $\begin{array}{l}\text { Number of co-morbidities } \\
0 \text { to } 2\end{array}$ & $188(58.2)$ & $115(61.2)$ & $73(38.8)$ & \\
$>2$ & $135(41.8)$ & $76(56.3)$ & $59(43.7)$ & 0.379 \\
\hline
\end{tabular}

Notes: *Poor adherence refers to patients with mean MARS score $<4.5$. **Good adherence refers to patients with mean MARS score $\geq 4.5$. $\wedge$ I missing data. Abbreviation: LABA, long acting $\beta$-agonists.

Table 2 Bivariate Analyses of Beliefs and Adherence

\begin{tabular}{|c|c|c|c|c|c|}
\hline Dimensions & $\begin{array}{l}\text { Patients Scoring Above } \\
\text { Scale Mid-Point (\%) }\end{array}$ & $\begin{array}{l}\text { All, Mean } \\
\text { (SD) }\end{array}$ & $\begin{array}{l}\text { Poor Adherence*, } \\
\text { Mean (SD) }\end{array}$ & $\begin{array}{l}\text { Good Adherence**, } \\
\text { Mean (SD) }\end{array}$ & $p$ \\
\hline \multicolumn{6}{|l|}{ IIIness perceptions (B-IPQ) } \\
\hline Consequence & 17.3 & $3.26(2.45)$ & $3.45(2.44)$ & $2.99(2.46)$ & 0.100 \\
\hline Timeline & 64.1 & $6.99(3.33)$ & $5.95(3.43)$ & $8.50(2.49)$ & $<0.001$ \\
\hline Control & 68.9 & $6.77(2.53)$ & $6.28(2.54)$ & $7.48(2.35)$ & $<0.001$ \\
\hline Identity & 15.8 & $3.39(2.25)$ & $3.58(2.17)$ & $3.13(2.33)$ & 0.079 \\
\hline \multicolumn{6}{|l|}{ Medication beliefs (BMQ) } \\
\hline Medication-Necessity & 67.5 & $3.43(0.8 I)$ & $3.19(0.80)$ & $3.77(0.7 \mathrm{I})$ & $<0.001$ \\
\hline Medication-Concerns & 30.7 & $2.67(0.74)$ & $2.84(0.73)$ & $2.44(0.69)$ & $<0.001$ \\
\hline
\end{tabular}

Notes: *Poor adherence refers to patients with mean MARS score $<4.5$. **Good adherence refers to patients with mean MARS score $\geq 4.5$.

Table 3 Logistic Regression: Factors Influencing ICS Adherence

\begin{tabular}{|c|c|c|c|c|}
\hline Variable & Poor Adherence* & Good Adherence** & Adjusted OR (95\% Cl) & $p$ \\
\hline \multicolumn{5}{|c|}{ Illness perceptions (B-IPQ), mean (SD) } \\
\hline Consequence & $3.45(2.44)$ & $2.99(2.46)$ & $0.90(0.79,1.04)$ & 0.142 \\
\hline Timeline & $5.95(3.43)$ & $8.50(2.49)$ & $1.22(1.10,1.35)$ & $<0.001$ \\
\hline Control & $6.28(2.54)$ & $7.48(2.35)$ & $1.04(0.92,1.17)$ & 0.581 \\
\hline Identity & $3.58(2.17)$ & $3.13(2.33)$ & $0.98(0.84,1.14)$ & 0.802 \\
\hline \multicolumn{5}{|c|}{ Medication beliefs (BMQ), mean (SD) } \\
\hline Medication-Necessity & $3.19(0.80)$ & $3.77(0.7 I)$ & $2.67(1.76,4.06)$ & $<0.001$ \\
\hline Medication-Concerns & $2.84(0.73)$ & $2.44(0.69)$ & $0.39(0.26,0.60)$ & $<0.001$ \\
\hline \multicolumn{5}{|c|}{ Inhaler medication, n (\%) } \\
\hline Combined ICS-LABA & $97(5 \mathrm{I} . \mathrm{I})$ & $93(48.9)$ & $2.50(1.4 I, 4.44)$ & 0.02 \\
\hline ICS monotherapy & $94(70.7)$ & $39(29.3)$ & I & - \\
\hline
\end{tabular}

Notes: *Poor adherence refers to patients with mean MARS score $<4.5$. **Good adherence refers to patients with mean MARS score $\geq 4.5$.

poorer adherence to ICS, but such patients were also less likely to adhere to other self-management behaviours such as routine doctor visits and the use of peak flow measurements. ${ }^{37}$

Our results also mirrored research that examined medication beliefs with adherence in younger adults. The stronger the belief in the necessity of ICS, the better the adherence. ${ }^{16,28,34}$ Among 352 Latvian patients with asthma (mean age 57.5 years), Smits et al showed that patients who felt that asthma medication was necessary for their health were more likely to be adherent to their treatment. ${ }^{34}$ Similarly, Ulrik et al showed that patients who agreed that controller therapy was an essential part of asthma management and that controller therapy was effective had better adherence based on a study of 509 Danish patients (age 18-45 years). ${ }^{38}$ Interestingly, Duarte-de-araújo et al found that patients with Chronic Obstructive Pulmonary Disease (COPD) who believed that their inhaled medication was 
necessary for treatment of their disease had better adherence as well. $^{39}$ This suggested that the positive association between beliefs on the necessity of inhaled medication with adherence may also be present in patients with obstructive lung diseases other than asthma.

On the other hand, our study showed the more concerns that patients had, the lower the adherence to ICS. This was similarly shown in studies among younger patients. ${ }^{16,29,34}$ Foot $\mathrm{H}$ et al in their study of 219 patients in Australia (mean age 39.8 years) showed patients who had more concerns about their ICS were less likely to adhere to their ICS as compared to patients who had fewer concerns. ${ }^{16} \mathrm{Up}$ to $42.0 \%$ of our multi-ethnic study population was worried about the long-term side effects of ICS, while $35.0 \%$ of them were concerned about becoming too dependent on them. Such worries were also reflected in a study by Merkenberg et al who showed that up to $44.6 \%$ of 238 Dutch patients (mean age 36.2 years) expressed worries about the long-term effects of $\mathrm{ICS},{ }^{28}$ while Ponieman et al showed that up to $37.0 \%$ of 261 American patients (mean age 48 years) feared developing addiction to them. ${ }^{29}$ In Asian communities, where the use of traditional treatment is prevalent, patients especially the elderly may perceive "western medication" to result in more side effects and medication dependency. ${ }^{15,30}$ This observation was reported by Chiu et al in their study on 1054 Asian patients: up to $40.0 \%$ of them agreed with the statement "I think herbal medicines are safer than inhalers" and this belief was associated with poorer ICS adherence. $^{15}$

The associations demonstrated between illness timeline, medication beliefs and ICS adherence among older adults were consistent with that seen in younger adults, suggesting that these findings may apply across a broad age spectrum. However, illness perceptions of "Identity", "Control" and "Consequences" dimensions were not shown to be associated with ICS adherence in this study. Illness perceptions influence on adherence may vary across age groups and older adults could interpret these dimensions of illness perceptions differently compared to younger adults. In addition, although illness perceptions can direct patients' self-management behaviours, their behaviours can also alter the expressions of their illness which may in turn reshape their perceptions.

The use of combined ICS-LABA medication seemed to influence medication adherence. Laforest et al also reported that French patients (mean age 53.8 years) receiving combined ICS-LABA therapy had better adherence compared to patients on ICS monotherapy. ${ }^{31}$ The prolonged bronchodilation effect of LABA allowed symptom relief which would lead to patients perceiving immediate benefits from the therapy. ${ }^{32}$ Meta-analyses also supported the superiority of combined ICS-LABA therapy over ICS monotherapy in terms of clinical efficacy, which in turn could have modulated patients' adherence to their medication. $^{33}$

\section{Strengths and Limitations}

This study explored adherence to ICS among older patients, a group with higher asthma morbidity as compared to younger patients.

Findings in this study need to be interpreted in light of its limitations. Medication adherence and beliefs were assessed using self-reported instruments, which may be subjected to recall bias. The use of an English-based questionnaire on older patients was potentially challenging, but the availability of validated instruments in Chinese and deployment of trained multi-lingual study team members had overcome the language barriers. Training of the study team by the principal investigator ensured consistency in administering the questionnaires. The study team also recognized the inherent biases in convenience sampling but the study population already comprised of a selected subset of the population, which limited its generalizability to the general population. Patients were identified in this study based on clinical diagnosis of asthma by physicians. The lack of spirometry evidence to support the diagnosis in $82 \%$ of the patients was a potential limitation. However, evidence also suggested that spirometry is not a sensitive tool to diagnose asthma and patients with asthma may demonstrate normal spirometry. 35,36

\section{Implications for Research and/or Practice}

The results showed the magnitude of poor ICS adherence among older patients with asthma. This should prompt review of the asthma counselling program. Asthma counselling should emphasize the chronic nature of asthma and the need for daily use of ICS even when asymptomatic. Addressing the patient's concerns with regards to worries about medication side effects and dependency is also essential. Regular counselling to correct erroneous medication beliefs and misperceptions can also be incorporated into home visit reviews, which may potentially improve asthma outcomes. $^{40}$ 
Nevertheless, little is known about the fluidity of illness perceptions and treatment beliefs. Patients undergo variable experiences in their lifetime, which can subsequently interfere with their understanding and impact their subsequent perceptions and beliefs. Whether the asthma counselling can permanently rectify any misperceptions and misbeliefs to achieve sustained adherence to ICS can be determined in future research.

\section{Conclusions}

Four in ten older patients with asthma were adherent to ICS. Good adherence to ICS was associated with perceived illness timeline and medication beliefs. Further research can look into developing and testing targeted interventions aimed at addressing these modifiable factors to improve adherence to ICS.

\section{Ethics Approval}

Ethics approval for this study was obtained from the SingHealth Centralized Institution Review Board (CIRB: 2016/3173/E).

\section{Acknowledgments}

The authors would like to acknowledge contributions by staff of SingHealth research department, Caris Tan YT and Usha $\mathrm{S}$ for providing administrative support, members of Outram polyclinic study team Wang XF, Sathiavani, Fadhilah, Seah AC, Ashma and members of Geylang polyclinic study team Lin XH, Lew SM, Farah and Kamala.

\section{Funding}

This study received funding from SingHealth Polyclinics research department. Funding number: SHP-SEED38 $-2016[7]$.

\section{Disclosure}

The authors report no conflicts of interest for this work.

\section{References}

1. Boulet L-P, Vervloet D, Magar Y, Foster JM. Adherence: the goal to control asthma. Clin Chest Med. 2012;33(3):405-417. doi:10.1016/j. ccm.2012.06.002

2. Brooks TL, Leventhal H, Wolf MS, et al. Strategies used by older adults with asthma for adherence to inhaled corticosteroids. $J$ Gen Intern Med. 2014;29(11):1506-1512. doi:10.1007/s11606-014-2940-8

3. Byer B, Myers LB. Psychological correlates of adherence to medication in asthma. Psychol Health Med. 2000;5(4):389-393. doi:10.1080/ 713690213
4. Zhang X, Morrison-Carpenter T, Holt JB, Callahan DB. Trends in adult current asthma prevalence and contributing risk factors in the United States by state: 2000-2009. BMC Public Health. 2013;13:1156. doi:10.1186/1471-2458-13-1156

5. Barnes CB, Ulrik CS. Asthma and adherence to inhaled corticosteroids: current status and future perspectives. Respir Care. 2015;60 (3):455-468. doi:10.4187/respcare.03200

6. Foster JM, Lavoie KL, Boulet LP. Treatment adherence and psychosocial factors in severe asthma. Eur Respir Monogr. 2011;51:28-49.

7. Gaude GS, Hattiholi J, Chaudhury A. Role of health education and self-action plan in improving the drug compliance in bronchial asthma. J Family Med Prim Care. 2014;3(1):33-38. doi:10.4103/22494863.130269

8. Gaude GS. Factors affecting non-adherence in bronchial asthma and impact of health education. Indian J Allergy Asthma Immunol. 2011;25(1):1-8.

9. Makela MJ, Backer V, Hedegaard M, Larsson K. Adherence to inhaled therapies, health outcomes and costs in patients with asthma and COPD. Respir Med. 2013;107(10):1481-1490. doi:10.1016/j. rmed.2013.04.005

10. Murphy AC, Proeschal A, Brightling CE, et al. The relationship between clinical outcomes and medication adherence in difficult-tocontrol asthma: table 1. Thorax. 2012;67(8):751-753. doi:10.1136/ thoraxjnl-2011-201096

11. Akinbami LJ, Moorman JE, Bailey C, et al. Trends in asthma prevalence, health care use, and mortality in the United States, 2001-2010. NCHS Data Brief. 2012;94:1-8.

12. Gillman A, Douglass JA. Asthma in the elderly. Asia Pac Allergy. 2012;2(2):101-108. doi:10.5415/apallergy.2012.2.2.101

13. Leventhal H, Phillips LA, Burns EJ. The Common-Sense Model of self-regulation (CSM): a dynamic framework for understanding illness self-management. $\quad J$ Behav Med. 2016;39(6):935-946. doi:10.1007/s10865-016-9782-2

14. Unni E, Shiyanbola OO. Clustering medication adherence behavior based on beliefs in medicines and illness perceptions in patients taking asthma maintenance medications. Curr Med Res Opin. 2016;32(1):113-121. doi:10.1185/03007995.2015.1105204

15. Chiu K-C, Boonsawat W, Cho S-H, et al. Patients' beliefs and behaviors related to treatment adherence in patients with asthma requiring maintenance treatment in Asia. $J$ Asthma. 2014;51 (6):652-659. doi:10.3109/02770903.2014.898772

16. Foot H, La Caze A, Cottrell N. Identifying the relationship between beliefs and medication adherence in asthma. Ann Allergy Asthma Immunol. 2017;119(3):284-295. doi:10.1016/j.anai.2017. 06.012

17. Cooper V, Metcalf L, Versnel J, Upton J, Walker S, Horne R. Patient-reported side effects, concerns and adherence to corticosteroid treatment for asthma, and comparison with physician estimates of side-effect prevalence: a UK-wide, cross-sectional study. NPJ Prim Care Respir Med. 2015;25:15026. doi:10.1038/ npjpcrm.2015.26

18. Foster JM, Smith L, Bosnic-Anticevich SZ, et al. Identifying patient-specific beliefs and behaviours for conversations about adherence in asthma. Intern Med J. 2012;42(6):e136-e144. doi:10.1111/ j.1445-5994.2011.02541.x

19. Horne R, Chapman SCE, Parham R, Freemantle N, Forbes A, Cooper V. Understanding patients' adherence-related beliefs about medicines prescribed for long-term conditions: a meta-analytic review of the necessity-concerns framework. PLoS One. 2013;8 (12):e80633. doi:10.1371/journal.pone.0080633

20. Horne R, Weinman J, Hankins M. Beliefs about medicines questionnaire: the development and evaluation of a new method for assessing the cognitive representation of medication. Psychol Health. 1999;14 (1):1-24. doi:10.1080/08870449908407311 
21. Van Steenis MN, Driesenaar JA, Bensing JM, et al. Relationship between medication beliefs, self-reported and refill adherence, and symptoms in patients with asthma using inhaled corticosteroids. Patient Prefer Adherence. 2014;8:83-91. doi:10.1016/S1081-1206(10)60532-7

22. Singstat.gov.sg. Statistics Singapore - latest data. [online]. Available from: https://www.singstat.gov.sg/publications/publications-andpapers/cop2010/cop2010adr. Accessed April 19, 2018.

23. Sofianou A, Martynenko M, Wolf MS, et al. Asthma beliefs are associated with medication adherence in older asthmatics. $J$ Gen Intern Med. 2012;28(1):67-73. doi:10.1007/s11606-012-2160-z

24. Horne R, Hankins M. The Medication Adherence Report Scale. Brighton, England: Center for Health Care Research; 2002.

25. Cohen JL, Mann DM, Wisnivesky JP, et al. Assessing the validity of self-reported medication adherence among inner-city asthmatic adults: the medication adherence report scale for asthma. Ann Allergy Asthma Immunol. 2009;103(4):325-331.

26. Weinman J, Petrie KJ, Moss-morris R, et al. The illness perception questionnaire: a new method for assessing the cognitive representation of illness. Psychol Health. 1996;11(3):431-445. doi:10.1080/ 08870449608400270

27. Broadbent E, Petrie KJ, Main J, et al. The brief illness perception questionnaire. J Psychosom Res. 2006;60(6):631-637. doi:10.1016/j. jpsychores.2005.10.020

28. Menckeberg TT, Bouvy ML, Bracke M, et al. Beliefs about medicines predict refill adherence to inhaled corticosteroids. J Psychosom Res. 2008;64(1):47-54. doi:10.1016/j.jpsychores.2007.07.016

29. Ponieman D, Wisnivesky JP, Leventhal H, Musumeci-Szabo TJ, Hal EA. Impact of positive and negative beliefs about inhaled corticosteroids on adherence in inner-city asthmatic patients. Ann Allergy Asthma Immunol. 2009;103(1):38-42. doi:10.1016/S1081-1206(10) 60141-X

30. Peltzer K, Pengpid S. Utilization and practice of Traditional/ Complementary/Alternative Medicine (T/CAM) in Southeast Asian Nations (ASEAN) member states. J Stud Ethno Med. 2015;9 (2):209-218. doi:10.1080/09735070.2015.11905437
31. Laforest L, El Hasnaoui A, Pribil C, et al. Asthma patients` selfreported behaviours toward inhaled corticosteroids. Respir Med. 2009;103(9):1366-1375. doi:10.1016/j.rmed.2009.03.010

32. Walters JAE, Wood-Baker R, Walters EH. Long-acting $\beta 2$-agonists in asthma: an overview of cochrane systematic reviews. Respir Med. 2005;99(4):384-395. doi:10.1016/j.rmed.2005.01.003

33. Shrewsbury S, Pyke S, Britton M. Meta-analysis of increased dose of inhaled steroid or addition of salmeterol in symptomatic asthma (MIASMA). BMJ. 2000;320(7246):1368-1373. doi:10.1136/bmj.320. 7246.1368

34. Smits D, Brigis G, Pavare J, Maurina B, Barengo NC. Factors related to good asthma control using different medical adherence scales in Latvian asthma patients: an observational study. NPJ Prim Care Respir Med. 2017;27(1):39. doi:10.1038/s41533-017-0042-x

35. Meneghini AC, Paulino ACB, Pereira LP, Vianna EO. Accuracy of spirometry for detection of asthma: a cross-sectional study. Sao Paulo Med J. 2017;135(5):428-433. doi:10.1590/1516-3180.2017.0041250517

36. Schneider A, Gindner L, Tilemann L, et al. Diagnostic accuracy of spirometry in primary care. BMC Pulm Med. 2009;9(31). doi:10. 1186/1471-2466-9-31

37. Halm EA, Mora P, Leventhal H, et al. No symptoms, no asthma: the acute episodic disease belief is associated with poor self-management among inner-city adults with persistent asthma. Chest. 2006;129 (3):573-580. doi:10.1378/chest.129.3.573

38. Ulrik CS, Backer V, Søes-Petersen U, et al. The patient's perspective: adherence or non-adherence to asthma controller therapy? J Asthma. 2006;43(9):701-704. doi:10.1080/02770900600925569

39. Duarte-de-Araújo A, Teixeira P, Hespanhol V, Correia-de-Sousa J. COPD: understanding patients' adherence to inhaled medications Int J Chron Obstruct Pulmon. 2018;13:2767-2773. doi:10.2147/ COPD.S160982

40. Muneswarao J, Hassali MA, Ibrahim B, et al. Effectiveness of home visits in adult patients with asthma: a systematic review of randomized controlled trials. J Allergy Clin Immunol. 2020. doi:10.1016/j. jaip.2020.05.032
Patient Preference and Adherence

\section{Publish your work in this journal}

Patient Preference and Adherence is an international, peer-reviewed, open access journal that focusing on the growing importance of patient preference and adherence throughout the therapeutic continuum. Patient satisfaction, acceptability, quality of life, compliance, persistence and their role in developing new therapeutic modalities and compounds to optimize clinical outcomes for existing disease states are major areas of interest for the journal. This journal has been accepted for indexing on PubMed Central. The manuscript management system is completely online and includes a very quick and fair peer-review system, which is all easy to use. Visit http:// www.dovepress.com/testimonials.php to read real quotes from published authors. 